\title{
Cognitive structures based on culinary success factors in the development of new dishes by Japanese chefs at fine dining restaurants
}

Hiroya Kawasaki*, Chinatsu Kasamatsu and Masahiko Nonaka

\begin{abstract}
Background: The aim of this study was to conceptualize a new dish design process used by highly reputable chefs at fine dining restaurants, using cognitive modeling methods, and prioritize the important culinary success factors (CSFs) of the cognitive structures involved in creating new dishes characteristic to Japanese chefs of Japanese and French cuisine in fine dining restaurants. We asked 12 chefs of Japanese cuisine and 7 chefs of French cuisine at fine dining restaurants to answer questionnaires designed according to the Decision-Making Trial and Evaluation Laboratory (DEMATEL) method. All participants were Japanese. We preselected CSFs via text mining, using the laddering method in discussions with 9 chefs of Japanese cuisine about 54 new dishes that they had created.

Results: We identified 10 CSFs, as follows: (1) utilization of main ingredient texture, (2) utilization of main ingredient flavor, (3) utilization of main ingredient umami, (4) featured main ingredient, (5) good pairings (complements) between main and secondary ingredients, (6) not too rich, (7) good balance, (8) cuisine more Japanese in style, (9) elegance, and (10) surprise. We then created a DEMATEL diagram as a visual representation of each chef's thinking pattern with respect to dish creation. In the average diagram of chefs of Japanese cuisine, "utilization of main ingredient flavor" held the greatest importance and was influenced most by "cuisine more Japanese in style" in dish creation. Therefore, making cuisine more Japanese in style would result in chefs of Japanese cuisine using the main ingredient's flavor. Therefore, chefs of Japanese cuisine believed that when a chef prioritized using the main ingredient's flavor in the creation of Japanese cuisine, the new dish would be valuable. In addition, the average diagram of chefs of French cuisine was created and compared to that of chefs of Japanese cuisine.

Conclusions: This study shows that the cognitive analysis of highly reputable chefs at fine dining restaurants can provide cognitive models of dish creation for 10 CSFs of Japanese chefs of Japanese and French cuisine and can be used as references for beginners creating the new dishes.
\end{abstract}

Keywords: Laddering, DEMATEL, Cognitive structure, Chefs, Culinary success factors

\section{Background}

"Select a focus area of an ingredient, what it is to be paired with, and how to cut it. Before you cook, you should consider and gather the threads of your story." ([1] Yoshihiro Murata, owner chef of Kikunoi).

It takes both culinary skills and excellent ideas to create a new dish. Normally, cooks have hardly any

\footnotetext{
* Correspondence: hiroya_kawasaki@ajinomoto.com

Institute for Innovation, Ajinomoto Co., Inc., 1-1, Suzuki-cho, Kawasaki-ku,
} Kawasaki-shi 210-8681, Japan opportunities to consider new dishes after graduating from culinary school and do not do so until they become section chefs. There are no guidelines, however, describing how to create new dishes; indeed, ways to devise novel dishes may stem from experience as a chef. The cognitive framework for creating these dishes may be formed by repeated criticism from customers or executive chefs, which should be incorporated into chefs' training quickly. Zopiatis provided 27 important professional factors of "chefs' competencies for success" using in-depth interviews [2]. In addition, the Research Chefs Association made a list of core competencies needed by research chefs. They interviewed chefs about which 
competencies they considered important for checklists or guidelines for training cooks [3-5]. They reported that the association membership categories, such as Chef, Food Science and Technology, or Culinology, affected knowledge levels in "food science" and "culinary arts" [6]. These reports may guide the definition of competencies for cooks. Chossat and Gergaud posited that creativity consists of introducing fundamental changes to traditional ways of cooking and analyzed the related strategies that are highly ranked in famous French guidebooks [7]. Michel et al. explored creative presentation by analyzing the visual presentation of food within Kandinsky's paintings [8]. Some reports analyzed the process of creating dishes at high-end restaurants, assessed through in-depth interviews or the analytic hierarchy process (AHP). They suggested that culinary creativity could be taught and is an important factor in culinary education $[9,10]$. In another study, culinary development competencies were examined using in-depth interviews with chefs, who discussed the possibility of training culinary creativity [11-13]. $\mathrm{Hu}$ extracted innovative culinary development (ICD) from in-depth interviews of international hotel chefs in Taiwan using the Delphi method and analytic network process (ANP) [14]. The 156 items for forming ICD competencies were categorized as culture (19 items), aesthetic (16 items), technology (21 items), products (24 items), services (14 items), management (34 items), and creativity (28 items) and were evaluated according to the degree of importance. Horng, in turn, reported that culinary creativity scores increased following creative culinary curriculum-based instruction [15]. These studies were based on the idea that culinary creativity was a core culinary competency. Their results suggested that it is essential to incorporate a culinary creativity curriculum into hospitality management coursework.

At a product level, Klosse et al. conducted interviews and identified six culinary success factors (CSFs) involved in chefs' development of products (dishes): (1) name and presentation befitting expectations, (2) appetizing smell suitable to the food, (3) good balance of flavor compounds in relation to the food, (4) presence of umami, (5) a mix of hard and soft textures apparent in the mouth, and (6) high flavor richness [16]. Although these factors may be critical to developing new dishes or improving existing ones, their interrelationships remain unclear.

Cognitive structures are the structured mental models used to collect and edit information from our environments, and understanding them allows us to develop effective learning strategies. Chefs cook on the basis of their cognitive structures, and elucidating these structures would benefit not only cooks but also research chefs and food scientists.

Laddering is a potential interviewing technique for exploring these cognitive structures [17]. During interviews, subjects are typically asked questions such as "Why is that important to you?" with the express goal of determining sets of linkages between key perceptual elements across a range of attributes $(\mathrm{A})$, consequences $(\mathrm{C})$, and values $(\mathrm{V})$ $[18,19]$. Laddering became popular during investigations into what participants deemed important according to the models of the means-end chain (MEC) theory. In a series of articles entitled "Challenging Kyoto Cuisine" in a monthly Japanese magazine for professional chefs, nine chefs of Japanese cuisine presented new dishes using theme ingredients while discussing and criticizing each other's performances. Laddering occurred naturally within these articles, with chefs discussing their attitudes to creating new dishes and the reasons why they appreciated particular creations. In our study, we applied the laddering technique to these discussions and identified factors that emerged as CSFs.

There are some techniques for developing mathematical models of decision making, such as the AHP [20], the interpretive structural modeling (ISM) [21], the fuzzy theory [22], and the Decision-Making Trial and Evaluation Laboratory (DEMATEL) method. The DEMATEL method consolidates a professional group's knowledge to identify causal relationships between complicated factors. This method can reduce the number of criteria required and identify directions for improvement. The factors with higher degrees of influence can be designated as key factors for improvement, and bolstering them can improve service quality in hotels or hospitals. Shieh et al. identified key success factors in hospitals using DEMATEL analysis of 19 service quality experts [23]. DEMATEL methods may be used in combination with importance-performance and gap analysis (IPGA) to improve service quality in high-end restaurants [24], the fuzzy Delphi method for restaurant space design [25], and ANP for airline safety evaluation [26]. Therefore, the DEMATEL method is appropriate in developing a cognitive model of chef creativity.

The aim of this study was to conceptualize new dish design processes of highly reputable chefs at fine dining restaurants, using cognitive modeling methods, and prioritize the important CSFs of the cognitive structures involved in creating new dishes characteristic of Japanese chefs of Japanese and French cuisines. The Japanese chefs of French cuisine spent many years in France and received French cuisine training. We adopted a tandem method, which included laddering and DEMATEL, to determine whether cognitive structures depend on training background. This article is based on a research project with goals including (1) pinpointing new CSFs involved in new dish creation by employing a laddering analysis of discussion articles written by chefs at fine dining restaurants, (2) developing DEMATEL questionnaires using the identified CSFs, (3) conducting surveys 
that revealed the cognitive structures employed by chefs at fine dining restaurants in creating new dishes, and (4) prioritizing important CSFs of the cognitive structures employed by Japanese chefs of Japanese or French cuisine.

\section{Results}

In the laddering survey, we identified phrases of $\mathrm{C}$ and V (Table 1). Ten major CSFs were identified:

Texture (1): Utilization of main ingredient texture. Flavor (2): Utilization of main ingredient flavor. Umami (3): Utilization of main ingredient umami. Main ingredient (4): Featured main ingredient. Good pairings (5): Good pairings (complements) between main and secondary ingredients.

Not too rich (6): Not too rich.

Good balance (7): Good balance.

Cuisine more Japanese in style (8): Cuisine more

Japanese in style.

Elegance (9): Elegance.

Surprise (10): Surprise.

DEMATEL questionnaires were constructed using these CSFs.

The total relation matrix and the sum of influences are seen in Tables 2 and 3. For chefs of Japanese cuisine (Table 2), texture (1) directly superseded flavor (2) and umami (3). The $R+C$ value indicates the importance of a CSF, while the $\mathrm{R}-\mathrm{C}$ value indicates the size of the direct effect of the CSF on other CSFs. A large negative value indicates that the CSF is highly influenced by other CSFs.

Figure 1 shows the digraph of causal relations between 10 CSFs in dish creation by chefs of Japanese cuisine. The dimension of cuisine more Japanese in style (8) has higher values of influence, indicating that it carries the most influence of all CSFs for chefs of Japanese cuisine creating new dishes; in this study, it functions as an original source of creativity. Generally, any pair of CSFs for cuisine more Japanese in style (8), umami (3), flavor (2), and good balance (7) were mutually influential. Other CSFs influenced texture (1). Flavor (2) was the most important CSF, and it was influenced more by cuisine more

\section{Table 1 Culinary success factors identified by laddering}

\begin{tabular}{ll}
\hline Consequences & Values \\
\hline $\begin{array}{l}\text { 1. Utilization of main ingredient } \\
\text { texture }\end{array}$ & $\begin{array}{l}\text { 5. Good pairings (complements) } \\
\text { between main and secondary } \\
\text { ingredients }\end{array}$ \\
$\begin{array}{ll}\text { 2. Utilization of main ingredient flavor } & \text { 6. Not too rich } \\
\begin{array}{l}\text { 3. Utilization of main ingredient } \\
\text { umami }\end{array} & \begin{array}{l}\text { 7. Good balance } \\
\text { 4. Featured main ingredient }\end{array} \\
& \begin{array}{l}\text { 8. Cuisine more Japanese in } \\
\text { style }\end{array} \\
& \text { 9. Elegance } \\
\text { 10. Surprise }\end{array}$
\end{tabular}

Japanese in style (8) than it was by other CSFs (Table 2). Relative to other CSFs, not too rich (6) was the least dependent on other CSFs. In sum, chefs of Japanese cuisine paid most attention to five causes (2, 3, 5, 6, and 8) rather than receivers $(1,4,7,9$, and 10), based on the $\mathrm{R}-\mathrm{C}$ values.

Figure 2 shows that cuisine more French in style (8) was not affected by other CSFs but affected flavor (2), umami (3), main ingredient (4), good pairings (5), good balance (7), and surprise (10) in chefs of French cuisine. Cuisine more French in style (8) was a key CSF, as it was not only a cause but also remains unaffected by the other criteria. The effect of surprise (10) was received by other CSFs in dish creation by chefs of French cuisine. Nevertheless, the importance of cuisine more French in style only ranked ninth. In contrast, flavor (2) was the most important CSF and affected good balance (7), good pairings (5), main ingredient (4), and umami (3). In dish creation by chefs of French cuisine, flavor (2) was influenced more by good balance (7) than it was by other CSFs (Table 3). In sum, chefs of French cuisine paid the most attention to six causes $(1,4,5,6,7$, and 8) rather than receivers $(2,3,7,9$, and 10$)$, based on the $R-C$ values.

\section{Discussion}

We applied the laddering technique to printed discussions with chefs at fine dining restaurants regarding the creation of new dishes and identified a number of CSFs including texture (1), flavor (2), umami (3), main ingredient (4), good pairings (5), not too rich (6), good balance (7), cuisine more Japanese in style (8), elegance (9), and surprise (10). Thereafter, we asked Japanese chefs at fine dining restaurants to answer the DEMATEL questionnaire to reveal the relationships between the CSFs. Cuisine more Japanese in style (8) exerted the most influence of all CSFs in chefs of Japanese cuisine creating new dishes; it was also mutually linked to umami (3) and flavor (2). Flavor (2) was the most important CSF according to chefs of Japanese cuisine. Similarly, cuisine more French in style (8) had the most influence among chefs of French cuisine and remained unaffected by the other CSFs, whereas flavor (2) was the most important CSF with the greatest negative prominence value.

1. Utilization of main ingredient texture. The CSF of texture (1) had the lowest influence among chefs of Japanese cuisine and was influenced more by flavor (2) than it was by other CSFs (Table 2). This means that chefs of Japanese cuisine believed that the more they used the flavor of the main ingredient in their dishes, the more the texture of the main ingredient was used. However, for chefs of French cuisine, texture (1) was one of the notable influencing factors and exerted a stronger influence on flavor 
Table 2 Total influence matrix of CSFs: Chefs of Japanese cuisine

\begin{tabular}{|c|c|c|c|c|c|c|c|c|c|c|c|c|c|c|}
\hline & 1 & 2 & 3 & 4 & 5 & 6 & 7 & 8 & 9 & 10 & Row sum & Column sum & $\mathrm{R}+\mathrm{C}$ & $\mathrm{R}-\mathrm{C}$ \\
\hline 1. Texture & 0.189 & 0.352 & 0.329 & 0.306 & 0.302 & 0.116 & 0.344 & 0.33 & 0.21 & 0.235 & 2.713 & 3.269 & 5.982 & -0.556 \\
\hline 2. Flavor & 0.427 & 0.525 & 0.618 & 0.515 & 0.546 & 0.291 & 0.653 & 0.636 & 0.532 & 0.361 & 5.104 & 4.785 & 9.889 & 0.319 \\
\hline 3. Umami & 0.404 & 0.625 & 0.454 & 0.543 & 0.535 & 0.206 & 0.557 & 0.59 & 0.432 & 0.42 & 4.766 & 4.398 & 9.164 & 0.368 \\
\hline 4. Main & 0.305 & 0.416 & 0.453 & 0.358 & 0.292 & 0.136 & 0.403 & 0.387 & 0.252 & 0.346 & 3.348 & 3.781 & 7.129 & -0.433 \\
\hline 5. Pairings & 0.356 & 0.555 & 0.456 & 0.35 & 0.403 & 0.251 & 0.551 & 0.472 & 0.393 & 0.3 & 4.087 & 3.969 & 8.056 & 0.118 \\
\hline 6. Not too rich & 0.237 & 0.317 & 0.295 & 0.214 & 0.192 & 0.106 & 0.315 & 0.312 & 0.264 & 0.13 & 2.382 & 2.002 & 4.384 & 0.38 \\
\hline 7. Good balance & 0.389 & 0.607 & 0.503 & 0.533 & 0.43 & 0.28 & 0.474 & 0.589 & 0.503 & 0.254 & 4.562 & 4.731 & 9.293 & -0.169 \\
\hline 8. Cuisine more Japanese in style & 0.416 & 0.648 & 0.599 & 0.568 & 0.465 & 0.293 & 0.643 & 0.494 & 0.531 & 0.282 & 4.939 & 4.52 & 9.459 & 0.419 \\
\hline 9. Elegance & 0.318 & 0.443 & 0.403 & 0.386 & 0.282 & 0.236 & 0.502 & 0.491 & 0.292 & 0.188 & 3.541 & 3.572 & 7.113 & -0.031 \\
\hline 10. Surprise & 0.228 & 0.297 & 0.288 & 0.196 & 0.334 & 0.087 & 0.289 & 0.219 & 0.163 & 0.148 & 2.249 & 2.664 & 4.913 & -0.415 \\
\hline
\end{tabular}

Threshold value: 0.37691 ; the values were marked when higher than the threshold value. The values in italics are above the average values for matrix.

(2) relative to that exerted on other CFSs; this influence was mutual (Table 3). This means that chefs of French cuisine believed that utilization of the texture and flavor of the main ingredient affected each other in dish creation.

2. Utilization of main ingredient flavor. The CSF of flavor (2) had the highest prominence value in chefs of both Japanese and French cuisine. This indicates that the chefs believed that prioritizing the use of the flavor of the main ingredient would increase the value of the dish in the creation of Japanese and French cuisine. Interestingly, for chefs of Japanese cuisine, flavor (2) had a higher influential value and was influenced more by cuisine more Japanese in style (8) than it was by other CSFs (Table 2), but among chefs of French cuisine, it was a negative influencing factor, and therefore a receiver factor, and it was influenced more by good balance (7) than it was by other CSFs (Table 3). These results suggest that chefs of both Japanese and French cuisine believed that the utilization of the flavor of the main ingredient was the most important CSF, but the CSFs that influenced this differed in dish creation.

3. Utilization of main ingredient umami. Umami is commonly said to be the main taste in Japanese soup stock, dashi, and in various stocks used in Western cuisine; the closest English terms to umami are "savory," "meaty," and "broth-like." Additionally, umami substances, such as glutamate and nucleotides, are present in many foods [27]. For chefs of both Japanese and French cuisine, umami (3) was a highly prominent CSF; among chefs of Japanese cuisine in particular, umami (3) had the highest influential value. However, in chefs of French cuisine, umami (3) was one of the receiver CSFs. Chefs of both Japanese and French cuisine believed that umami was important to the design of a palatable dish, but the chefs of French cuisine did not rate umami highly. This may have been related to the availability of various umami taste seasonings, such as kombu seaweed, dried bonito, soy sauce, and miso for chefs of Japanese cuisine.

Table 3 Total influence matrix of CSFs: Japanese chefs of French cuisine

\begin{tabular}{|c|c|c|c|c|c|c|c|c|c|c|c|c|c|c|}
\hline & 1 & 2 & 3 & 4 & 5 & 6 & 7 & 8 & 9 & 10 & Row sum & Column sum & $\mathrm{R}+\mathrm{C}$ & $\mathrm{R}-\mathrm{C}$ \\
\hline 1. Texture & 0.165 & 0.390 & 0.314 & 0.276 & 0.347 & 0.082 & 0.315 & 0.111 & 0.251 & 0.380 & 2.631 & 2.103 & 4.734 & 0.528 \\
\hline 2. Flavor & 0.271 & 0.348 & 0.441 & 0.392 & 0.403 & 0.164 & 0.370 & 0.198 & 0.362 & 0.449 & 3.398 & 3.481 & 6.879 & -0.083 \\
\hline 3. Umami & 0.154 & 0.360 & 0.231 & 0.258 & 0.324 & 0.072 & 0.236 & 0.166 & 0.230 & 0.354 & 2.385 & 3.236 & 5.621 & -0.851 \\
\hline 4. Main & 0.303 & 0.425 & 0.406 & 0.309 & 0.267 & 0.086 & 0.288 & 0.244 & 0.273 & 0.417 & 3.018 & 2.875 & 5.893 & 0.143 \\
\hline 5. Pairings & 0.244 & 0.423 & 0.403 & 0.244 & 0.320 & 0.152 & 0.341 & 0.180 & 0.280 & 0.411 & 2.998 & 2.767 & 5.765 & 0.231 \\
\hline 6. Not too rich & 0.171 & 0.251 & 0.230 & 0.208 & 0.150 & 0.061 & 0.200 & 0.065 & 0.255 & 0.238 & 1.829 & 1.016 & 2.845 & 0.813 \\
\hline 7. Good balance & 0.250 & 0.435 & 0.408 & 0.363 & 0.372 & 0.158 & 0.231 & 0.129 & 0.342 & 0.364 & 3.052 & 2.556 & 5.608 & 0.496 \\
\hline 8. Cuisine more French in style & 0.226 & 0.338 & 0.375 & 0.333 & 0.350 & 0.078 & 0.262 & 0.115 & 0.249 & 0.327 & 2.653 & 1.341 & 3.994 & 1.312 \\
\hline 9. Elegance & 0.177 & 0.315 & 0.242 & 0.219 & 0.165 & 0.126 & 0.210 & 0.073 & 0.144 & 0.251 & 1.922 & 2.478 & 4.400 & -0.556 \\
\hline 10. Surprise & 0.142 & 0.196 & 0.186 & 0.165 & 0.177 & 0.037 & 0.103 & 0.060 & 0.092 & 0.133 & 1.291 & 3.324 & 4.615 & -2.033 \\
\hline
\end{tabular}

Threshold value: 0.25177 ; the values were marked when higher than the threshold value. The values in italics are above the average values for matrix. 

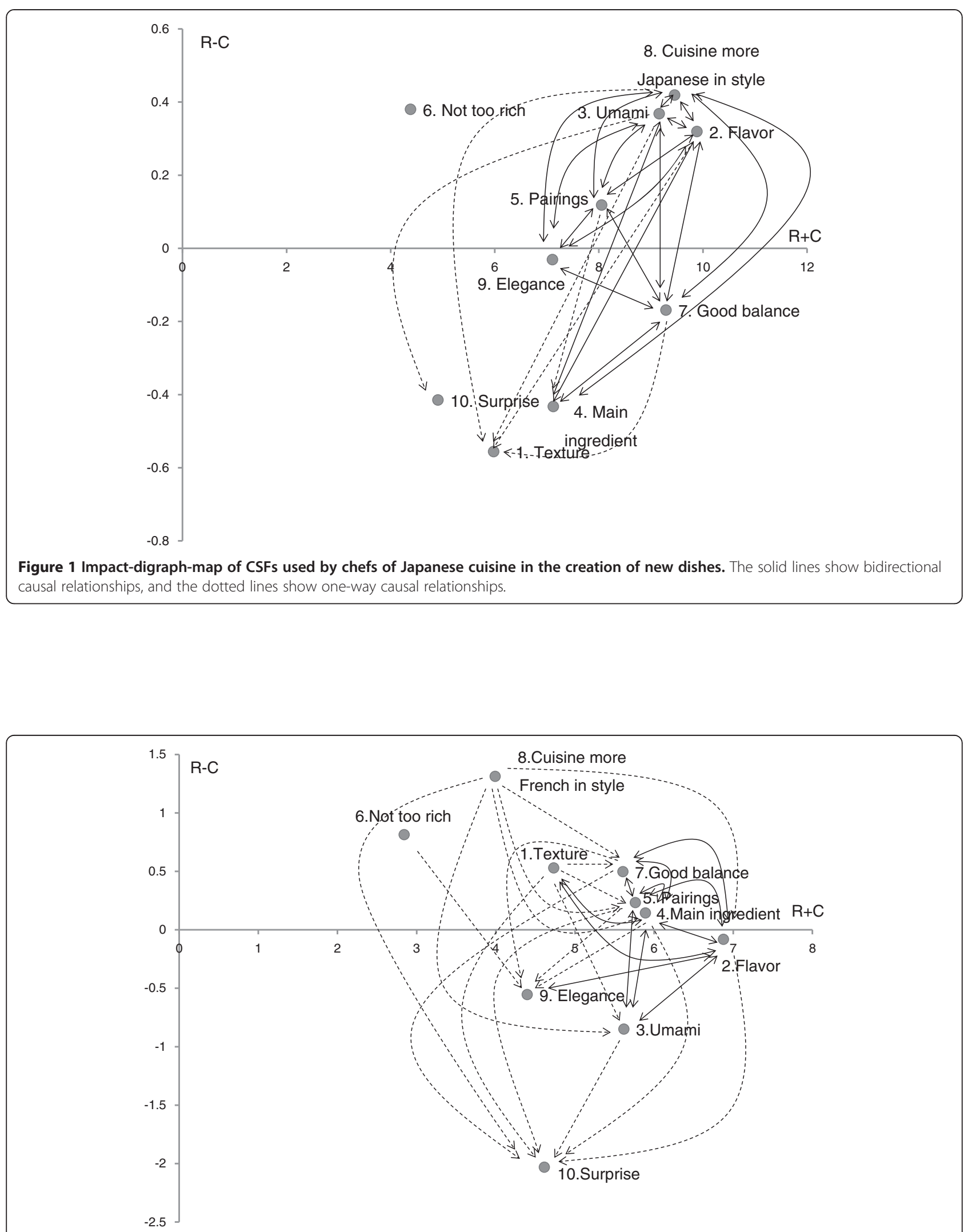

Figure 2 Impact-digraph-map of CSFs used by chefs of French cuisine in the creation of new dishes. The solid lines show bidirectional causal relationships, and the dotted lines show one-way causal relationships. 
4. Featured main ingredient. The featured main ingredient (4) CSF indicates that the main ingredient clearly stands out in the dish. For chefs of Japanese cuisine, the main ingredient (4) did not have a high prominence value and was characterized by a low influential value. However, for chefs of French cuisine, the main ingredient ranked second in prominence and was one of the essential influencers.

5. Good pairings (complements) between main and secondary ingredients. When the main ingredient in a new dish is specified, it is essential to choose the secondary ingredients carefully. For chefs of both Japanese and French cuisine, good pairings (5) had high influential and prominence value. Among chefs of Japanese cuisine, cuisine more Japanese in style (8) and good pairings (5) were mutually influential; however, among chefs of French cuisine, cuisine more French in style was not connected to the good pairings CSF.

6. Not too rich. The not too rich CSF (6) represents the preference that a dish is not too rich or heavy and, in many cases, neither too strong in taste nor cooked with too much fat. In chefs of both Japanese and French cuisine, not too rich (6) showed a high influential value. While it was independent of other CSFs for chefs of Japanese cuisine, it affected elegance (9) for chefs of French cuisine. Chefs of Japanese cuisine do not use much fat, and dishes do not tend to be rich. Chefs of French cuisine tend to express elegance (9) by making dishes that deemphasize richness.

7. Good balance. This factor indicates that there are no salient flavor or texture components in the dish, and the dish is well balanced overall. Chefs of both Japanese and French cuisine thought this CSF important, based on its high influential value. Chefs of Japanese cuisine believed that good balance (7) was one of the receiver groups and shared a mutually influential relationship with the cuisine more Japanese in style CSF (8). Chefs of French cuisine considered good balance (7) an influential factor, which was affected by the cuisine more French in style CSF (8). These results suggest that, for chefs of Japanese cuisine, the better the balance of the dish, the more Japanese the dish is with respect to style. For chefs of French cuisine, a better balance is not linked to French cuisine style. To create a dish with good balance, chefs could align various flavors with similar strengths when they use strongly flavored ingredients, as indicated in the laddering survey.

8. Cuisine more Japanese (or French) in style. This factor is quite complex and pertains to the dish being based on Japanese or French food culture, tradition, materials, condiments, and presentation. The fact that this CSF has the highest influential value for chefs of both Japanese and French cuisine suggests that chefs were thoroughly aware of their culinary heritage. It bears noting, however, that while Japanese-style cuisine ranked second in importance for chefs of Japanese cuisine, Frenchstyle cuisine only ranked ninth among chefs of French cuisine. For chefs of Japanese cuisine, cuisine more Japanese in style exerted the strongest influence on the use of main ingredient flavor, relative to that exerted on other CSFs (Table 2). This result suggests that chefs of Japanese cuisine believed that creating dishes more Japanese in style would result in the use of the flavor of the main ingredient. For chefs of French cuisine, cuisine more French in style exerted the strongest influence on utilization of main ingredient umami, relative to that exerted on other CSFs (Table 3). This result suggests that chefs of French cuisine believed that creating dishes more French in style would result in the use of the umami of the main ingredient.

9. Elegance. In dishes at fine dining restaurants, elegance refers to the creation of a sophisticated impression. For chefs of both Japanese and French cuisine, elegance (9) was a receiver criterion. Elegance was affected by other CSFs, such as flavor (2), umami (3), good pairings (4), good balance (7), and cuisine more Japanese in style (8) for chefs of Japanese cuisine. For chefs of French cuisine, flavor (2), main ingredient (4), good pairings (5), and not too rich (6) affected elegance (9), but umami (3) and good balance (7) did not. In particular, flavor (2) was the most effective CSF in elegance (9) in chefs of both Japanese and French cuisine, who believed that the more chefs utilized the main ingredient flavor, the more elegant the dish would be. To introduce elegance to a dish, chefs could remove overpowering or less desirable flavors or use a mild umami taste, as indicated in the laddering survey.

10. Surprise. This factor indicates unusual food experiences in dishes. For chefs of both Japanese and French cuisine, surprise (10) was a receiver CSF. Among chefs of Japanese cuisine, surprise (10) was only affected by umami (3). However, for chefs of French cuisine, surprise (10) was affected by other CSFs in dish creation and most strongly affected by flavor (2). These results suggested that utilization of the main ingredient's umami taste resulted in surprise in the dish for chefs of Japanese cuisine, and chefs of French cuisine tended to express surprise through the utilization of the main ingredient's flavor. To create a surprise dish, chefs could make dishes with flavors that could not be 
determined by customers through merely viewing the food, as indicated in the laddering survey.

The DEMATEL method was used to reduce the number of criteria and find a direction for improvement of the elements [28]. To compare the cognitive structures used by chefs of Japanese cuisine to those of chefs of French cuisine, each factors' characteristics were summarized (Table 4). We found that flavor (2), umami (3), and cuisine more Japanese in style (8) may be key criteria because of their high influential and prominence value, as rated by chefs of Japanese cuisine. Among chefs of French cuisine, French-style cuisine (8) was the most influential CSF; however, its prominence value was not particularly high. The most important factor was flavor (2), which had the highest prominence value and a highly negative influential value in chefs of French cuisine.

\section{Conclusions}

We applied the laddering technique to discussions concerning new dish creation by Japanese chefs at fine dining restaurants and extracted the most influential and prominent factors as 10 CSFs. In the average diagram of chefs of Japanese cuisine, cuisine more Japanese in style exerted the strongest influence over other CSFs, while the utilization of main ingredient texture was affected by other CSFs in the creation of dishes. The utilization of main ingredient flavor held the most important and was influenced more strongly by cuisine more Japanese in style than it was by other CSFs. Thus, chefs of Japanese cuisine believed that prioritizing the use of the flavor of the main ingredient would increase the value of a new

Table 4 Differences in cognitive structure between chefs of Japanese and French cuisine

\begin{tabular}{|c|c|c|}
\hline CSFs & $\begin{array}{l}\text { Chefs of Japanese } \\
\text { cuisine }\end{array}$ & $\begin{array}{l}\text { Japanese chefs } \\
\text { of French cuisine }\end{array}$ \\
\hline $\begin{array}{l}\text { 1. Utilization of main } \\
\text { ingredient texture }\end{array}$ & Receiver factor & Cause factor \\
\hline $\begin{array}{l}\text { 2. Utilization of main } \\
\text { ingredient flavor }\end{array}$ & Key factor & $\begin{array}{l}\text { Most important } \\
\text { factor }\end{array}$ \\
\hline $\begin{array}{l}\text { 3. Utilization of main } \\
\text { ingredient umami }\end{array}$ & Key factor & Receiver factor \\
\hline 4. Featured main ingredient & Receiver factor & Cause factor \\
\hline $\begin{array}{l}\text { 5. Good pairings (complements) } \\
\text { between main and secondary } \\
\text { ingredients }\end{array}$ & Cause factor & Cause factor \\
\hline 6. Not too rich & Independent factor & Cause factor \\
\hline 7. Good balance & Receiver factor & Cause factor \\
\hline $\begin{array}{l}\text { 8. Cuisine more Japanese } \\
\text { (or French) in style }\end{array}$ & Key factor & $\begin{array}{l}\text { Most influential } \\
\text { factor }\end{array}$ \\
\hline 9. Elegance & Receiver factor & Receiver factor \\
\hline 10. Surprise & Receiver factor & Receiver factor \\
\hline
\end{tabular}

dish in the creation of Japanese cuisine. For chefs of French cuisine, cuisine more French in style exerted the strongest influence over other CSFs, while surprise was affected by other CSFs in the creation of dishes. The use of main ingredient flavor was the most important CSF, and it was influenced more strongly by good balance than it was by other CSFs.

Cognitive structures are structured mental models that are used to collect and edit information from the external world [23]. We found that chefs at fine dining restaurants employ different cognitive structures when devising new dishes, and differences in cuisine genre and training background affected not only cooking techniques, ingredients, and condiments but also the mental models employed by the chefs in creating new dishes. Understanding the prioritized CSFs in dish creation by chefs at Japanese fine dining restaurants may help beginners to create new dishes and assist chefs who are interested in Japanese cuisine styles. While this study provides new insight into CSFs, further research including a greater number and variety of chefs as participants is required to confirm the robustness and validity of our results.

\section{Methods}

\section{Research samples and data collection}

A regular feature entitled "Challenging Kyoto Cuisine" in Professional Cooking, a monthly magazine targeted at Japanese chefs, was used in the laddering survey. The articles involved chefs (owner chefs or executive chefs) at fine dining restaurants, who created new dishes over the course of 20 months, from January 2011 to July 2012, using 10 themed ingredients. Survey items were developed from the printed articles.

In the DEMATEL questionnaire survey, we interviewed Japanese chefs of Japanese and French cuisine (owner chefs or executive chefs) at fine dining restaurants (Table 5). All participants were male, 37-64 years of age, and familiar with the creative development process. They provided informed consent prior to participating in the study. The studies were reviewed and approved by the Managing Committee of the Institute

Table 5 Chefs interviewed and their ratings in the Michelin Guide 2013

\begin{tabular}{lcc}
\hline Michelin rating & $\begin{array}{c}\text { No. of chefs of } \\
\text { Japanese cuisine }\end{array}$ & $\begin{array}{c}\text { No. of chefs of } \\
\text { French cuisine }\end{array}$ \\
\hline$* * *$ & 4 & 0 \\
$* *$ & 2 & 2 \\
$*$ & 2 & 5 \\
0 & 4 & 0 \\
Total chefs interviewed & 12 & 7 \\
\hline
\end{tabular}


for Innovation of Ajinomoto Co., Inc. and were in compliance with the Helsinki Declaration.

\section{Laddering: identifying CSFs}

Laddering is an individual interview technique employed in order to understand how consumers translate the characteristics of a given product and follows MEC theory [29]. Generally, this involves the interviewer asking a series of directed questions such as "Why is this important to you?" to determine sets of connections between a range of $\mathrm{A}, \mathrm{C}$, and $\mathrm{V}$.

Based on this concept, we extracted phrases pertaining to "consequences or reasons" (C) in 20 monthly issues of the "Challenging Kyoto Cuisine" publication. We then identified the phrases describing attributes or ladderdown factors and values and ladder-up factors in this context. For example, from "The aroma of the Sudachi is good; it is elegant and the cuisine is more Japanese in style," we extracted "good aroma" as a consequence and "elegant" and "the cuisine is more Japanese in style" as values. Factors with the same meaning were grouped together, and each group was labeled and aggregated to provide frequency data. We selected phrases that were used as CSFs more than four times. Laddering results are shown in Table 1. For chefs' convenience, the final length of the questionnaire was considered in determining the number of CSFs. The top 10 CSFs for the questionnaire were chosen according to the frequency of appearance.

\section{DEMATEL method: clarifying the interrelations between CSFs}

The DEMATEL method was developed by the Science and Human Affairs Program of the Battelle Memorial
Institute of Geneva, to elucidate intertwined and complex problems [23]. Traditional methods, such as the AHP, are based on the assumption that elements are independent of one another. Being a structural modeling technique, however, this method is capable of identifying interdependence between elements within a cause-and-effect relationship diagram. To represent the strength of the effects of individual elements, a causal relation diagram is used as a directed, rather than undirected, graph. In this study, we created DEMATEL questionnaire sheets using the CSFs identified through laddering methods (Figure 3). The DEMATEL questionnaires relied on respondent chefs' selfreported responses to questions, such as "When you create a new dish, how much does the 'not too rich' factor affect the 'cuisine more Japanese in style' of the dish?" For chefs of French cuisine, we replaced "cuisine more Japanese in style" with "cuisine more French in style." The evaluation scale ranged from 0 to 3 ( $0=$ no influence, $1=$ low level of influence, 2 = high level of influence, and $3=$ very high level of influence), and each DEMATEL survey session lasted 20-30 min. No participant chefs requested the meanings or definitions of any CSF. The steps in the DEMATEL method were based on Shieh et al. [23], as follows: step 1: calculate the original average matrix, step 2: normalize the initial direct-relation matrix, step 3: compute the total relation matrix, step 4: produce the causal diagram, and step 5: set up a threshold value.

\section{Step 1: Calculating the original matrix}

Each chef was asked to evaluate the direct influence of any two CSFs according to their experience. The notation of $x_{i j}$ shows the degree to which chefs thought that factor $i$ influenced factor $j$. For each chef, an $n \times n$

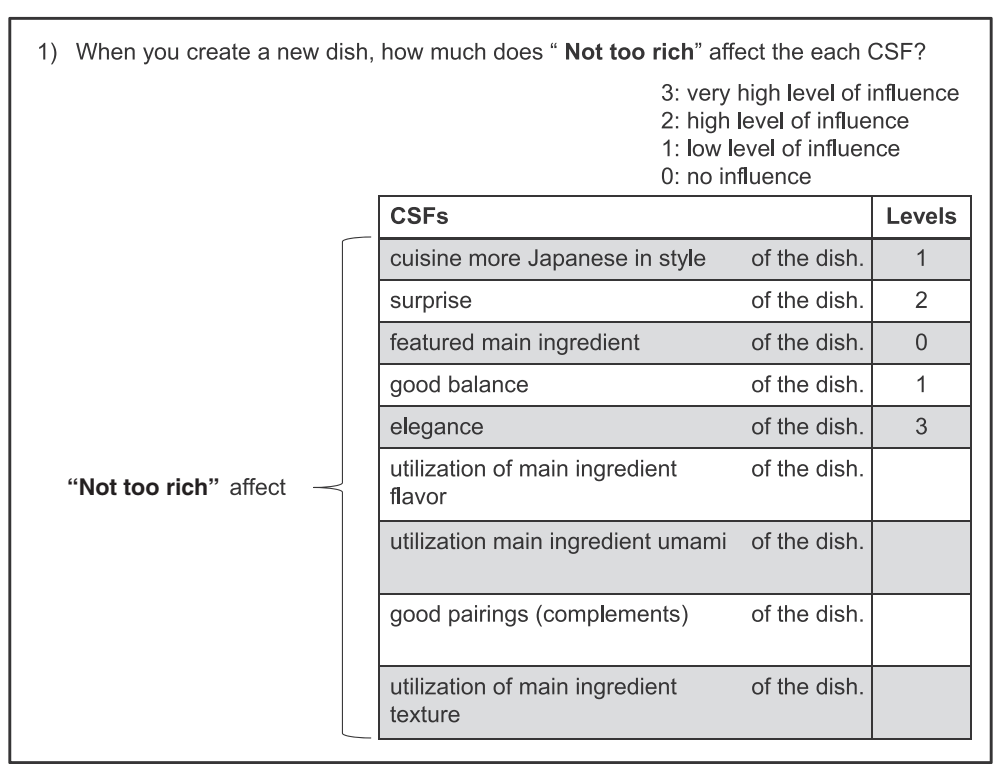

Figure 3 An example of the DEMATEL questionnaire. 
nonnegative matrix can be denoted as $X^{k}=\left[x_{i j}^{k}\right]$, with $1 \leq k \leq H$, where $n$ is the number of factors. Thus, $X^{1}, X^{2}, X^{3} \ldots X^{H}$ are the matrices for $H$ chefs. The average matrix $A=\left[a_{i j}\right]$ can be computed by averaging the $H$ chefs' value matrices, as follows:

$$
a_{i j}=\frac{1}{H} \sum_{k=1}^{H} x_{i j}^{k}
$$

\section{Step 2: Normalizing the initial direct-relation matrix}

A direct influence matrix $D$ may be obtained by normalizing the average matrix $A$

$$
D=A \times S
$$

where $S$ is a constant, which is calculated as follows:

$$
S=\frac{1}{\max _{1 \leq i \leq n} \sum_{j=1}^{n} a_{i j}} .
$$

\section{Step 3: Computing the total relation matrix}

The total relation matrix $T$ is also an $n \times n$ matrix and is given as $T=D(I-D)^{-1}$, in which $I$ is the identity matrix.

\section{Step 4: Producing a causal diagram}

The sums of rows and columns in the total relation matrix $T$ are separately represented as vectors $R$ and $C$. Suppose $\mathrm{R}_{i}$ is the sum of the $i$ th row of matrix $T$, then $\mathrm{R}_{i}$ shows the sum of direct and indirect effects of factor $i$ on the other factors. If $C_{j}$ denotes the column sum of the $j$ th column of matrix $T$, then $C_{j}$ shows the sum of direct and indirect effects of the other factors on factor $j$. When $j=i,\left(\mathrm{R}_{i}+\mathrm{C}_{i}\right)$ indicates an index of the strength of influences, $\left(\mathrm{R}_{i}+\mathrm{C}_{i}\right)$ shows the degree to which factor $i$ affects other factors, and if $\left(\mathrm{R}_{i}-\mathrm{C}_{i}\right)$ is negative, then factor $i$ is being influenced by other factors. The digraph may be obtained by plotting the dataset of $(R+C, R-C)$. The horizontal axis vector $(\mathrm{R}+\mathrm{C})$ is "Prominence" and indicates the degree of criterion importance. The vertical axis $(\mathrm{R}-\mathrm{C})$ is "Relation" and indicates the degree of criterion net effect. Specifically, if $\mathrm{R}-\mathrm{C}$ is positive, the criterion belongs to the cause group, which influences other CSFs, and if it is negative, the criterion belongs to the effect group, which is influenced by other CSFs.

\section{Step 5: Setting up a threshold value}

Matrix $T$ provides information regarding the influence that one element has on other elements. Because it is necessary to set a threshold for excluding negligible effects of several criteria, only those elements with influence equal to or exceeding the threshold value are displayed in the digraph. In this study, the threshold was set by calculating the average value of the elements in matrix $T$.

\section{Abbreviations}

AHP: Analytic hierarchy process; CSF: Culinary success factor; DEMATEL: DecisionMaking Trial and Evaluation Laboratory; ANP: Analytic network process; ICD: Innovative culinary development; IPGA: Importance-performance and gap analysis; ISM: Interpretive structural modeling; MEC: Means-end chain.

\section{Competing interests}

The authors declare that they have no competing interests.

\section{Authors' contributions}

$\mathrm{HK}, \mathrm{CK}$, and MN conceived the idea for the study and designed the details. HK conducted the study and analyzed the data. HK wrote the manuscript. HK, CK, and $\mathrm{MN}$ read and approved the final version of the manuscript.

\section{Authors' information}

$\mathrm{HK}$ is a researcher at the Institute for Innovation, Ajinomoto Co., Inc CK is a principal researcher at the Institute for Innovation, Ajinomoto Co., Inc. $\mathrm{MN}$ is a general professional at the Institute for Innovation, Ajinomoto Co., Inc.

\section{Acknowledgements}

The authors would like to thank Prof. Hideo Jingu from the Research Laboratory for Affective Design Engineering, Kanazawa Institute of Technology, for consultation on the experimental method. In addition, the authors would like to thank Prof. Toshiki Yamaoka from the Department of Design and Information Sciences, Wakayama University, for donating the DEMATEL method analysis software. The authors confirm that they received no external funding for this research.

Received: 5 August 2014 Accepted: 13 November 2014 Published: 12 January 2015

\section{References}

1. Meeting of Shibata Integrated Japanese Culinary Techniques. Challenging Kyoto cuisine. In: Yodono K, editor. Professional Cooking. Tokyo: Shibata Publishing Co.,Ltd; 2012. p. 85-9.

2. Zopiatis A. Is it art or science? Chef's competencies for success. Int J Hosp Manag. 2010;29:459-67.

3. Cheng M, Ogbeide G-CA, Hamouz FL. The development of culinary arts and food science into a new academic discipline-culinology. J Culin Sci Technol. 2011;9:17-26.

4. Bissett RL, Cheng MSH, Brannan RG. A qualitative assessment of culinary science competencies defined by the Research Chefs Association. J Culin Sci Technol. 2010;7:285-93.

5. Birdir K, Pearson TE. Research chefs' competencies: a Delphi approach. Int J Contemp Hospit Manag. 2000;12:205-9.

6. Bissett RL, Cheng MSH, Brannan RG. A quantitative assessment of the Research Chefs Association core competencies for the practicing culinologist. J Food Sci Educ. 2010;9:11-8.

7. Chossat V, Gergaud $O$. Expert opinion and gastronomy: the recipe for success. J Cult Econ. 2003;27:127-41

8. Michel C, Velasco C, Gatti E, Spence C. A taste of Kandinsky: assessing the influence of the artistic visual presentation of food on the dining experience. Flavour. 2014:3:7.

9. Ottenbacher M, Harrington RJ. The innovation development process of Michelin-starred chefs. Int J Contemp Hosp Manag. 2007;19:444-60.

10. Peng $K-L$, Lin $M-C$, Baum $T$. The constructing model of culinary creativity: an approach of mixed methods. Qual Quant. 2013;47:2687-707.

11. Hu M-L. Discovering culinary competency: an innovative approach. J Hosp Leis Sport Tour. 2010;9:65-72.

12. Horng J-S, Hu M-L. The creative culinary process: constructing and extending a four-component model. Creat Res J. 2009;21:376-83.

13. Horng J-S. The mystery in the kitchen: culinary creativity. Creat Res J. 2008;20:221-30.

14. Hu M-L. Developing a core competency model of innovative culinary development. Int J Hosp Manag. 2010;29:582-90.

15. Horng J-S, Hu M-L. The surprise of creative culinary curriculum on creative culinary process and performance. J Hosp Leis Sport Tour. 2009;8:34-46. 
16. Klosse PR, Riga J, Cramwinckel AB, Saris WHM. The formulation and evaluation of culinary success factors (CSFs) that determine the palatability of food. Food Serv Technol. 2004;4:107-15.

17. Reynolds TJ. Laddering theory, method, analysis, and interpretation. J Advert Res. 1988:28:11-31.

18. Veludo-de-Oliveira TM, Ikeda AA. Discussing laddering application by the means-end chain theory. Qual Rep. 2006;11:626-42.

19. Roininen K, Arvola A, Lähteenmäki L. Exploring consumers' perceptions of local food with two different qualitative techniques: laddering and word association. Food Qual Prefer. 2006;17:20-30.

20. Lee $W-S$, Huang AY, Chang Y-Y, Cheng C-M. Analysis of decision making factors for equity investment by DEMATEL and analytic network process. Expert Syst Appl. 2011;38:8375-83.

21. Chuang H-M, Lin C-K, Chen D-R, Chen Y-S. Evolving MCDM applications using hybrid expert-based ISM and DEMATEL models: an example of sustainable ecotourism. Sci World J. 2013;2013:1-18.

22. Rabiee A, Sarafrazi A, Khanmohammadi E, Jafarzadeh AH. Analysis of internal relationships of decision-making criteria under crisis situations using fuzzy DEMATEL method. Int J Econ Manag Soc Sci. 2013;2(June):230-6.

23. Shieh $\mathrm{J}-\mathrm{I}, \mathrm{Wu} \mathrm{H}-\mathrm{H}$, Huang K-K. A DEMATEL method in identifying key success factors of hospital service quality. Knowledge-Based Syst. 2010;23:277-82.

24. Cheng C-C, Chen C-T, Hsu F-S, Hu H-Y. Enhancing service quality improvement strategies of fine-dining restaurants: new insights from integrating a two-phase decision-making model of IPGA and DEMATEL analysis. Int J Hosp Manag. 2012;31:1155-66.

25. Horng J-S, Liu C-H, Chou S-F, Tsai C-Y. Creativity as a critical criterion for future restaurant space design: developing a novel model with DEMATEL application. Int J Hosp Manag. 2013;33:96-105.

26. Liou JJH, Tzeng G-H, Chang H-C. Airline safety measurement using a hybrid model. J Air Transp Manag. 2007;13:243-9.

27. Yamaguchi S, Ninomiya K. Umami and food palatability. J Nutr. 2000;130:921S-6.

28. Tzeng G, Chiang C, Li C. Evaluating intertwined effects in e-learning programs: a novel hybrid MCDM model based on factor analysis and DEMATEL. Expert Syst Appl. 2007:32:1028-44.

29. Veludo-de-Oliveira TM, Ikeda AA, Campomar MC. Laddering in the practice of marketing research: barriers and solutions. Qual Mark Res An Int J. 2006;9:297-306.

doi:10.1186/2044-7248-4-1

Cite this article as: Kawasaki et al.: Cognitive structures based on culinary success factors in the development of new dishes by Japanese chefs at fine dining restaurants. Flavour 2015 3:1.

\section{Submit your next manuscript to BioMed Central and take full advantage of:}

- Convenient online submission

- Thorough peer review

- No space constraints or color figure charges

- Immediate publication on acceptance

- Inclusion in PubMed, CAS, Scopus and Google Scholar

- Research which is freely available for redistribution 